\title{
Nonverbal Reactions to Conversational Interruption: A Test of Complementarity Theory and the Status/Gender...
}

Article in Journal of Nonverbal Behavior · December 2010

DOI: 10.1007/s10919-010-0091-0

\section{CITATIONS}

8

4 authors, including:

\section{Sally D Farley}

University of Baltimore

18 PUBLICATIONS 157 CITATIONS

SEE PROFILE
READS

139
Mark F. Stasson

Metropolitan State University

36 PUBLICATIONS 830 CITATIONS

SEE PROFILE

Some of the authors of this publication are also working on these related projects:

Project

Are nonverbal engagement signals or self-reported attitudes better predictors of behavior? View project 


\title{
Nonverbal Reactions to Conversational Interruption: A Test of Complementarity Theory and the Status/ Gender Parallel
}

\author{
Sally D. Farley $\cdot$ Amie M. Ashcraft • Mark F. Stasson • \\ Rebecca L. Nusbaum
}

Published online: 16 July 2010

(C) Springer Science+Business Media, LLC 2010

\begin{abstract}
The present research examined nonverbal reactions to conversational interruption (a status-organizing cue). We predicted that the nonverbal reactions to interruption (versus a control condition) would show a different pattern of results than gender differences. Participants $(N=150)$ were paired with one of four confederates and randomly assigned to either an interruption or control condition. Nine nonverbal behavioral reactions were coded by independent raters. Participants responded to interruption with reciprocal interruptions and increased nodding, as compared to a control condition. Gender differences diverged from those associated with condition. Women smiled, agreed, nodded, and laughed more than men, showing evidence of a greater attempt to facilitate the flow of conversation. We discuss these findings with regard to the dimensions of affiliation and verticality.
\end{abstract}

Keywords Interruption - Nonverbal behavior · Status · Complementarity · Gender

This research is a component of the first author's doctoral dissertation at Virginia Commonwealth University. The findings relating to how interrupters and their targets were perceived were published in the Journal of Nonverbal Behavior by the first author in 2008.

S. D. Farley $(\bowtie) \cdot$ R. L. Nusbaum

Division of Applied Behavioral Sciences, University of Baltimore, 1420 N. Charles Street, Baltimore, MD 21201, USA

e-mail: sfarley@ubalt.edu

A. M. Ashcraft

Sociometrics Corporation, Los Altos, CA, USA

M. F. Stasson

Metropolitan State University, St. Paul, MN, USA 


\section{Introduction}

In the "dance" of interpersonal communication, we are highly influenced by the behaviors of our conversational partners (Strong et al. 1988). The past 50 years have yielded a spate of theoretical frameworks attempting to best predict our nonverbal reactions in various situations (Patterson 2006). Many of the models focus their attention on nonverbal signals of involvement or intimacy and offer predictions with regard to when these behaviors (such as eye contact, leaning forward) are likely to be reciprocated (e.g., Burgoon's interaction adaptation theory; see Patterson). Other models have incorporated a vertical dimension (related to hierarchy, status, dominance) along with the horizontal dimension, suggesting that both dimensions need to be considered in order to determine likely nonverbal reactions.

Complementarity theory is one such theory, arguing that our behavioral repertoire is, to a certain extent, constrained by our partners' responses along two orthogonal dimensions: control and affiliation (Kiesler 1983; Strong et al. 1988). While there are some subtle distinctions in terminology between the interpersonal circle (Kiesler 1983), interpersonal theory (Sadler and Woody 2003; Strong et al. 1988), and complementarity theory (Stapel and Van der Zee 2006), generally these different conceptualizations offer overlapping predictions. Complementarity theory predicts that positive and negative behaviors tend to elicit corresponding positive and negative reactions (Sadler and Woody 2003) and that dominant behaviors elicit submissive responses and vice versa (Strong et al. 1988). Thus, one's behavior influences the other's, showing similar levels of affiliation and opposing levels of dominance (Sadler and Woody 2003). In this paper, we will describe nonverbal behaviors (NVBs) ranging from warm/friendly to cold/hostile as reflecting affiliation and behaviors linked with status, dominance, and power as reflecting verticality (Hall et al. 2005).

The mimicry paradigm, however, predicts that because similarity communicates connectedness, we have a non-conscious tendency to imitate the behavior of those around us, regardless of the valence of the behavior (Chartrand and Bargh 1999; Stapel and Van der Zee 2006). When NVBs vary only on the affiliative dimension, complementarity theory and mimicry both predict reciprocation. For example, one study found that participants reacted to "warm" (smiling, nodding, attentive) confederates with more eye contact, smiling, and nodding than to "cold" confederates who frowned and shook their heads (Ho and Mitchell 1982). However, complementarity theory and mimicry have contrary predictions concerning the vertical dimension; dominant behavior should elicit reciprocal dominant responses according to mimicry, but submissive behaviors according to complementarity.

As supportive evidence for dominance complementarity, Tiedens and Fragale (2003) investigated nonverbal reactions to postural expansion, a behavior that is generally associated with verticality, but not affiliation (Hall et al. 2005). In Experiment 1, participants were more likely to complement (decrease their personal space), as opposed to mimic (expand their personal space) confederates who adopted expansive postures. In Experiment 2, participants who were experimentally induced to adopt different postures liked confederates more when confederates complemented versus mimicked their posture. Tiedens' subsequent research (Tiedens et al. 2007) demonstrated that this preference for dominance complementarity extends to people with whom we expect to interact. That is, the higher one's self-reported dominance and warmth, the higher one rated an expected interaction partner on submissiveness and warmth. 
Both complementarity and mimicry theories have substantial empirical support (Bluhm et al. 1990; Chartrand and Bargh 1999; Moscowitz et al. 2007; Sadler and Woody 2003; Strong et al. 1988; Tiedens and Fragale 2003), so attention should be devoted to when mimicry or complementarity is more likely to occur. Situational contexts such as the relationship between the interactants, the setting (work or social), and interaction goals (Patterson 2006) have been found to moderate the extent to which complementarity is observed (Moscowitz et al. 2007; Tracey 1994). Furthermore, other research has emphasized the interactionist perspective, maintaining that predictions about nonverbal behavior are more accurate when accounting for both situational influences and personality differences (Aries et al. 1983; Burgoon and Dunbar 2000).

The purpose of the present research is to examine the nonverbal reactions to conversational interruption and to determine the extent to which these reactions fit within complementarity theory. In a previous publication (Farley 2008), the effects of interruption on self-reported perceptions of status and likability were reported (Experiment 2), and some of these findings will be revisited here because it will aid in the interpretation of the nonverbal patterns. Nonetheless, one difficulty with our present task of connecting various behaviors with complementarity is that it relies upon the assumption that we know what the nonverbal signals of dominance are.

Social psychologists have attempted for decades to identify the explicit meanings associated with various NVBs, but this task is made more complicated by the fact that most NVBs are discouragingly polysemous (Burgoon and Dillman 1995; Hall 2006; Tannen 1993; Tiedens and Fragale 2003), situationally variable, and inconsistent. For example, one's interactional goals (e.g., to get along) may be discordant with one's affect (I really don't like you), so there may be a disconnect between observed NVBs and emotional states (a point made by Patterson 2006). Hall et al. (2005) also noted the importance of proximal states (motivations, emotions, and roles) in the display of NVBs. In an individual lower in verticality, increased smiling may reflect anxiety or desire to appease; in an individual higher in verticality, smiling may be a way to increase the pleasantness of the work environment. Because of these many complications, nonverbal researchers advocate the method of evaluating the pattern of nonverbal behaviors as an aggregate (Burgoon and Dillman 1995; Burgoon and Le Poire 1999; Hall 2006). For our purposes, however, it is important to briefly summarize the trends of associations between specific NVBs and dimensions of verticality because our dependent measures were nonverbal reactions.

Conversational interruption was the primary nonverbal behavior of interest in this study. Reactions to interruption in conversation depend in large part upon how they are perceived by the target, because interruptions, like many NVBs, can communicate both affiliation and dominance. Research has demonstrated that positive interruptions (which are sometimes anticipatory, an attempt to finish another's thoughts) and supportive interruptions ("I totally agree with that") are evaluated positively by targets of interruptions (Tannen 1993). Indeed, in some groups, high rates of this participatory type of interruption are actually normative (as in some groups of closely knit female friends) (Aries 1996). However, deep interruptions which involve a topic change (LaFrance 1992) and intrusive interruptions, which intrude into the crux of another person's point (James and Clarke 1993), are consistently associated with perceived and actual verticality (Anderson and Leaper 1998; Hall et al. 2005). For example, Farley (2008) and others (LaFrance; Robinson and Reis 1989) who conducted experimental research involving systematic interruption found that interrupters were perceived as significantly more dominant, confrontational, influential, and assertive than the targets of their interruption and non-interrupting confederates. Participants rated themselves as less influential, dominant, and competent when 
they were interrupted than when they were not, showing the status-organizing effects of interruption (Farley).

Verticality can be communicated with a variety of other nonverbal signals. Observers believe that individuals high in verticality nod and laugh more (Hall et al. 2005), have more open postures (Aguinis and Henle 2001), touch others more, touch themselves less (Burgoon and Dillman 1995; Jones and Remland 1993), and smile less (Hall et al. 2005) than low verticality individuals. However, the relationship between verticality and smiling has been particularly inconsistent (Hall et al. 2002a, b).

Questions about gender differences in NVB inevitably surface in discussions of statusrelated differences. Despite Henley's $(1977,1995)$ assumption that status differences are responsible for observed gender differences, there is a lack of parallelism between men and high-status individuals and women and low-status individuals (Hall and Friedman 1999; Hall et al. 2005; Mulac and Bradac 1995). As strong evidence in support of this notion, gender effects actually became stronger when status effects were removed (Hall \& Friedman).

Some findings do differentiate men and women and high and low-status individuals as Henley $(1977,1995)$ predicted. Specifically, men have been found to display some dominant nonverbals, such as displaying more open postures (Aries 1982), interrupting more (Anderson and Leaper 1998; Hall 2006; Kennedy and Camden 1983; Smith-Lovin and Brody 1989), displaying shorter speech latency (Kollock et al. 1985), and disagreeing more (Carli 1989) than women (especially when paired with other men).

However, two of the behaviors more common in women's language, nodding and laughter, are actually associated with higher perceived verticality (Hall 2006), although these do not always signify greater status. Finally, there are a number of gender differences that are possibly unrelated to verticality. Despite the lack of association between actual status and verticality (Hall et al. 2005), women smile more than men (Halberstadt and Saitta 1987; Hall 2006; McAdams et al. 1984). Women also laugh more (Bilous and Krauss 1988; McAdams et al. 1984) and engage in more self-touch than men (Hall 2006; Smith-Lovin and Brody 1989). Evidently, the empirical support for the parallelism hypothesis is tenuous. Nonetheless, the present research offers an additional opportunity to investigate the tendency for gender differences to mirror status differences. Specifically, we can determine if the nonverbal behaviors of women are similar to the nonverbal behaviors of the targets of interruption, since they rated themselves lower in status than their interrupting interaction partners (Farley 2008).

Overall, the purpose of this research was to evaluate the nonverbal reactions to conversational interruption using complementarity theory and as a guiding theoretical framework. Research has consistently linked conversational interruption to verticality. Hall et al. (2005) and Farley (2008) showed that intrusive interruption operates as a statusorganizing cue. However, research has also linked intrusive interruption to the affiliative dimension. Individuals who intrude into their interaction partner's comments are disliked and viewed as disrespectful, rude, confrontational, and competitive (Farley 2008; LaFrance 1992).

Previous research testing mimicry and complementarity have traditionally utilized nonverbal behaviors that were associated with affiliation only (and not verticality), verticality only (and not affiliation), or neither (e.g., foot movement in Chartrand and Bargh 1999). Because intrusive interruption is associated with both verticality and affiliation, and because complementarity theory predicts reciprocity on the affiliative dimension, but complementarity on the vertical dimension, hypotheses about reciprocal interruption may depend upon which of these dimensions is more salient. 
If intrusive interruption serves as a status-organizing cue, and verticality is more salient, complementarity theory predicts that a negative dominant behavior such as interruption (Farley 2008; LaFrance 1992) should elicit negative submissive reactions (Sadler and Woody 2003; Strong et al. 1988).

Specifically, Hypothesis 1 predicted that in the interruption condition, the pattern of nonverbal reactions would consist of fewer reciprocal interruptions, less nodding and laughing, fewer open postures, more smiling, more self-touch, longer latency before speaking, more agreement, and less disagreement.

If the affiliative component of interruption is more salient, such that what is most obvious in the interaction is the rude, competitive nature of the interruptions, then complementarity theory (and mimicry) would predict that this hostility would be reciprocated. One relevant feature of this experiment is that participants believed they were interacting with a fellow student to discuss their attitudes toward an article. In short, they believed they were peers, equal in status, so it is likely that interruptions were perceived as illegitimate (and rude) power attempts (Wagner and Berger 1997), which may make the hostility aspect of the interruptions more salient. In addition, repeated intrusive interruption is likely to activate competitive motives when it interferes with task goals (as in, "I was told to discuss this article and I am not able to get my point across"). For these reasons, we also anticipated that one possible reaction to interruption is reciprocal interruption.

Hypothesis $1 \mathrm{~b}$ specified that participants would interrupt the confederates more in the interruption condition than in the control condition. Our prediction for participant gender is consistent with previous research.

Hypothesis 2 predicted that regardless of condition, women were expected to smile, nod, self-touch, laugh, and agree more than men. We predicted that men would interrupt more, sit with more open postures, speak more quickly than women, and disagree more than women.

While many of these behaviors were predicted to show parallelism, some were expected to show opposite gender/status patterns (nodding and laughter).

\section{Method}

\section{Participants}

A total of 187 Virginia Commonwealth University students participated in this research in return for partial course credit. Of the 187, 27 were omitted from coding due to suspicion of the purpose of the study or brevity of the interaction. Furthermore, we omitted an additional 10 participants because of technical malfunctions with audio/video equipment and framing issues. Included in the remaining 150 participants were 63 men and 87 women who were randomly assigned to the interruption $(n=91)$ and control conditions $(n=49)$.

\section{Design and Procedure}

The experiment was a 2 (condition: interruption and control) x 2 (participant gender) x 2 (confederate gender) between-subjects experimental design. In both the interruption and control conditions, participants read an article from USA Today regarding remedial education (Welsh 1999) and discussed the article with a male or female confederate, who 
delivered scripted roles. For example, one argument made by the confederates was "I always thought that the reasoning was, people who pay their tuition deserve to sit in on classes, but if they don't pass the class, then oh well, they don't deserve that piece of paper." Additional detail on the script and training of the confederates is described in Farley (2008) (Experiment 2). Two female and two male research assistants acted as confederates.

The interaction between the participant-confederate pairs was videotaped (Farley 2008). To provide structure for the interactions, experimenters instructed the dyads to focus on arguments against the article. In the control condition, the confederates allowed participants to fully complete their thoughts before confederates spoke, so speech alternated between confederate and participant. In the interruption condition, confederates were instructed to interrupt 8 out of 10 of the participants' statements. Interruptions were operationally defined as overlaps of speech 2 seconds or approximately 15 words (whichever came first) into the participant's utterance (Farley 2008), so they were intended to be deep and intrusive. When participants were reluctant to give up the floor, confederates were trained to repeat the first couple of words over and over again until the participants stopped talking, so successful interruptions were attempted, but were not always achieved. In a few circumstances, targets of interruption occasionally completed their statements regardless of interruption attempts. Trials were terminated after the completion of all confederate arguments or after 10 seconds of silence, whichever came first. Then the confederate left the room to allow the participant adequate time to complete a post-experimental questionnaire which assessed items related to status and likability (described in Farley 2008).

\section{Dependent Measures}

Two independent raters coded eight nonverbal behaviors (smiling, nodding, posture, latency, laughing, interruption, agreements, and disagreements) and an additional two raters coded self-touch and interruption. Most of the behaviors were coded for frequency during the interaction, and then converted to rates as a function of time (smiling, nodding, laughter, agreement, disagreement, self-touch, and interruption). For example, regardless of duration, research assistants coded the number of times that participants laughed, nodded, or smiled during the interaction; the counts were then converted to rates per minute. We operationally defined reciprocal interruption as the number of overlaps initiated by the participant, excluding back-channel utterances (e.g. "mm-hmm"). Agreements were the number of instances in which the participant, while speaking, indicated agreement with the confederate, e.g., "I think you are right, and . .." Disagreements were the number of instances in which the participant disagreed with the confederate, e.g., "Well, I'm not sure about that ..." Participants' postures were assessed after each argument and the number of open postures (sitting with his/her arms not crossed, with at least one arm not touching the torso) were summed for each participant. Latency was defined as the amount of time that elapsed after the confederate spoke his or her fifth argument and before the participant began speaking. This occurred after three interruptions in the interruption condition. Self-touch was defined as the number of times the participant made contact with his/her body above the waist (a table prevented us from viewing self-touch below the waist).

Pearson correlation coefficients were computed to assess interrater reliability of the coding of nonverbal behaviors. Coefficients were generally strong for eight of the nonverbal behaviors, ranging from .70 for self-touch to .97 for smiling, so the frequencies of 
the two raters were averaged before the variables were converted to rates. The correlation for interruption was not acceptable $(r=.59)$, so two additional independent raters recoded this variable. The interrater reliability of two of the four coders met acceptable levels, $r=.74$, so the average of these coders' interruptions were then converted to rate of interruption.

\section{Results}

To determine if the interruption manipulation was successful, participants were asked if they noticed if their partner interrupted them during conversation. The vast majority of participants were correct about their condition (88\%); that is saying "yes" when in interruption condition and "no" in control condition. Of those who were incorrect, $6 \%$ failed to notice when interruption occurred or perceived interruption when none occurred, and $6 \%$ were not sure.

To correct for the time of the interaction, the frequencies of nonverbal behavior were converted to rates as a function of time. Because the variables tended towards positive skewness (e.g., most people nodded between 0 and 1 times per minute) and because the initial analyses revealed a violation of the homogeneity of variance assumption for most variables, we completed square root transformations of the data. These transformations were largely successful, and so we utilized the transformed data for our analyses. However, the descriptive statistics that are described are rates as a function of time.

The analyses were 2 (participant gender) x 2 (condition: interruption versus control) x 2 (confederate gender) between-subject analyses of variance. For reciprocal interruption, the main effect of condition was significant, but in support for Hypothesis $1 \mathrm{~b}$, $F(1,141)=107.5, p<.001, \eta_{\mathrm{p}}^{2}=.43$. Participants interrupted confederates significantly more in the interruption condition $(M=1.13, \mathrm{SD}=.75)$ than in control $(M=.17$, $\mathrm{SD}=.16)$, but no other effects were significant for interruption.

The three-way interaction for laughter was significant, $F(1,141)=4.13, p=.04$, $\eta_{\mathrm{p}}^{2}=.03$. We split the file by condition to determine the pattern of effects. In the control condition, a main effect for gender emerged with female participants laughing more than male participants, regardless of confederate gender, $F(1,55)=4.13, p=.047, \eta_{\mathrm{p}}^{2}=.07$. But in the interruption condition, confederate gender and participant gender interacted, $F(1,86)=7.92, p=.006, \eta_{\mathrm{p}}^{2}=.08$. Female interrupters elicited relatively similar levels of laughter in male and female participants. However, women laughed much more than men did in reaction to male interrupters. See Figure 1 for a comparison of laughter in the interruption and control conditions. A main effect for participant gender also emerged in the complete analysis, $F(1,141)=6.27, p=.01, \eta_{\mathrm{p}}^{2}=.04$, as women laughed $(M=.30$, $\mathrm{SD}=.41)$ more than men $\operatorname{did}(M=.14, \mathrm{SD}=.27)$, in keeping with Hypothesis 2.

A three-way interaction was also found for nodding, but this effect was marginally significant, $F(1,141)=3.67, p=.058, \eta_{\mathrm{p}}^{2}=.03$. As with laughter, in the control condition, there was no interaction between confederate and participant gender, women simply nodded more than men, supporting Hypothesis $2, F(1,55)=6.85, p=.01, \eta_{\mathrm{p}}^{2}=.11$. The interaction was significant in the interruption condition, $F(1,86)=7.37, p=.008$, $\eta_{\mathrm{p}}^{2}=.08$. Both men and women nodded more with interrupters of the same-gender in comparison to the other gender. See Figure 2 for nodding in the interruption and control conditions. Main effects for the complete analysis were also found for condition, $F(1,141)=4.95, p=.03, \eta_{\mathrm{p}}^{2}=.03$, and participant gender, $F(1,141)=4.23, p=.04$, $\eta_{\mathrm{p}}^{2}=.03$. Participants nodded more in the interruption condition $(M=6.11, \mathrm{SD}=5.14)$ 

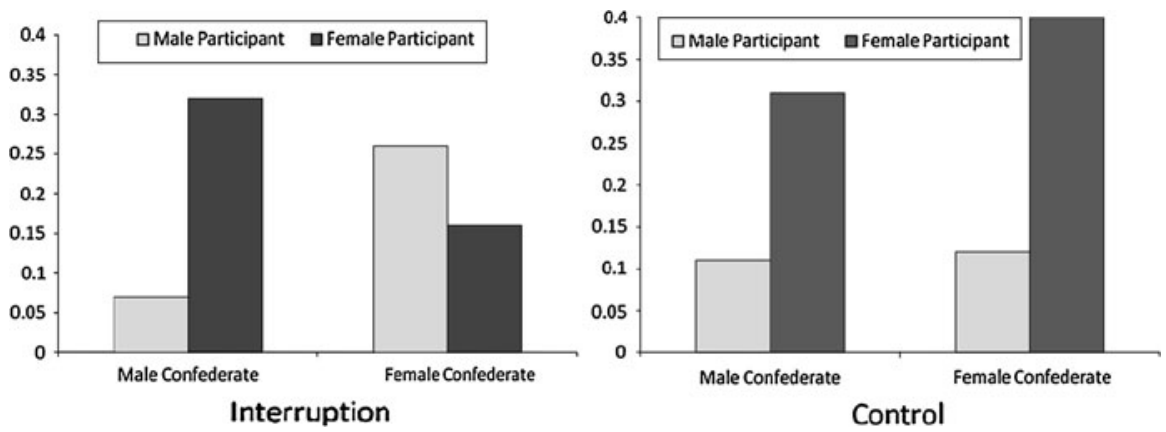

Fig. 1 Rate of laughter as a function of confederate gender and participant gender in the interruption condition (left) and control condition (right)
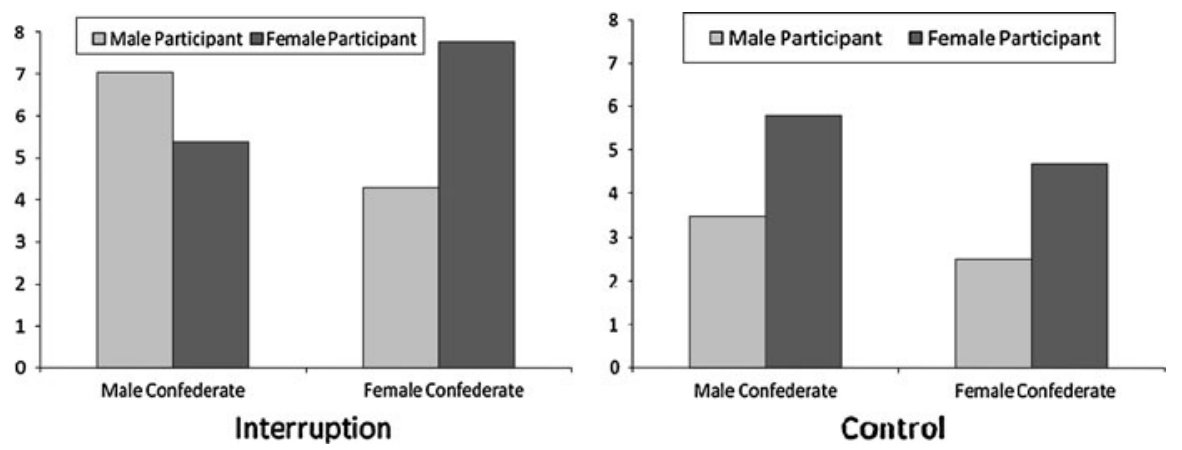

Fig. 2 Rate of nodding as a function of confederate gender and participant gender in the interruption condition (left) and control condition (right)

than the control $(M=4.10, \mathrm{SD}=3.04)$, which was counter to Hypothesis 1 , and women nodded more $(M=5.90, \mathrm{SD}=4.71)$ than men $(M=4.32, \mathrm{SD}=4.15)$, in support of Hypothesis 2.

Consistent with Hypothesis 2, we found main effects for participant gender for smiling, $F(1,142)=4.60, p=.03, \eta_{\mathrm{p}}^{2}=.03$, and agreement, $F(1,142)=5.58, p=.02, \eta_{\mathrm{p}}^{2}=.04$, as women smiled $(M=.43, \mathrm{SD}=.58)$ and agreed more $(M=1.19, \mathrm{SD}=.58)$ than men $(M=.31, \mathrm{SD}=.49 ; M=1.00, \mathrm{SD}=.51$, smiles and agreement respectively). We found no other significant effects for these variables. In terms of disagreement, only the main effect for confederate gender achieved significance, $F(1,142)=5.05, p=.03, \eta_{\mathrm{p}}^{2}=.03$. Participants disagreed with female confederates more $(M=.17, \mathrm{SD}=.21)$ than male confederates $(M=.14 \mathrm{SD}=.27)$.

With regard to latency, we found a two-way interaction between confederate gender and condition, $F(1,131)=9.05, p=.003, \eta_{\mathrm{p}}^{2}=.07$. In the interruption condition, participants started to speak more quickly when they were interrupted by men $(M=2.40, \mathrm{SD}=3.52)$ than women $(M=3.61, \mathrm{SD}=3.58)$. In the control condition, participants started to speak more quickly when talking with a female confederate $(M=2.86, \mathrm{SD}=3.19)$ than a male confederate $(M=8.44, \mathrm{SD}=13.67)$. For self-touch, a marginally significant main effect was observed for participant gender, $F(1,132)=2.91, p=.09, \eta_{\mathrm{p}}^{2}=.02$, as women 
engaged in more self-touch $(M=3.25, \mathrm{SD}=2.28)$ than men $(M=2.49, \mathrm{SD}=2.08)$. There were no significant effects observed for posture.

\section{Discussion}

In the self-reported findings from this experiment (Experiment 2 in Farley 2008), participants rated confederates as significantly higher in verticality when confederates interrupted, and rated themselves as lower in verticality when they were targets of interruption. As a result, this experiment offers us a unique opportunity to determine if self-reported perceptions of verticality (from Farley) correlate with nonverbal differences. In keeping with complementarity theory, Hypothesis 1a predicted that participants would react to the perceived power signal of interruption with putative submissive nonverbal behavior (fewer interruptions, less nodding and laughing, fewer open postures, more smiling, more selftouch, longer latency before speaking, more agreement, and less disagreement). Hypothesis $1 \mathrm{~b}$ predicted higher rates of reciprocal interruption in the interruption condition than the control condition. The gender prediction, Hypothesis 2, hypothesized that women would smile, nod, self-touch, laugh, and agree more than men, but that men would interrupt more, sit with more open postures, speak more quickly, and disagree more than women.

Contrary to the writings of Henley $(1977,1995)$, this experiment provides little evidence for a parallelism between gender and status differences. Consistent with Hypothesis 2 , women in this experiment nodded, smiled, self-touched, laughed and agreed more than men, regardless of condition. However, the significant effects for condition, which should have revealed status differences, showed a different pattern of results. Participants interrupted confederates more and nodded more in the interruption condition than in the control condition. No other significant main effects for condition emerged. If status differences were responsible for observed gender differences, one would predict that women and targets of interruption would display similar nonverbal reactions. In addition, despite Henley's notion that nodding represented evidence of deference and submissiveness, Hall et al. (2005) have found that those who nod more are perceived as more powerful, not less. It is important to remember that it is possible for "women's speak" to be both different from men's, but powerful in its own right (Mulac and Bradac 1995).

Rather than taking a passive stance and submitting to men who are presumed to have more power and status in society, women are active contributors to conversation, showing strength in their attempts at solidarity. Indeed, linguists and psychologists alike have long regarded women as performing more "conversational work" than men (Kollock et al. 1985), meaning that women fill in silences, facilitate conversation, and otherwise make attempts to make conversations run smoothly (Aries 1987). Perhaps this is related to the widely documented tendency for women to possess a relationship or communal orientation in groups and for men to possess an agentic or task-oriented style (Abele 2003). The NVBs that differentiated women from men in this experiment, greater smiling, laughing, nodding, and agreement, taken together as a package, convey encouragement, intimacy, connectedness, and support (Aries 1987), and it is important to reemphasize that it is unfair to equate these behaviors with submissiveness (Hall 2006).

The results from this experiment provide more support for Hypothesis $1 \mathrm{~b}$ than Hypothesis 1a. Despite participants' self-report indications that they viewed interrupters as having more status than themselves, they responded with dominant NVBs (reciprocal interruption and nodding) instead of submissiveness. In this circumstance, participants appear to be asserting themselves nonverbally despite their self-reported decreased status 
and these nonverbal "power moves" may act as a mechanism for status enhancement. This finding is consistent with Dunbar's dyadic power theory which predicts that nonverbal displays of dominance are more likely in equal-status conditions, where individuals are vying for power (Dunbar et al. 2008). In addition, participants in this experimental situation might have perceived the repeated interruption as illegitimate, and thus increased their interruption and nodding to communicate status (Ridgeway 1987). In support of this notion, in the interruption condition, higher rates of interruption were associated with higher ratings of perceived confederate disrespect (which was measured in Farley 2008), $r(74)=.24, p=.04$, and disagreement, $r(87)=.28, p<.01$. The higher the reciprocal interruption, the more disagreement, and the more the confederates were viewed as disrespectful (e.g., selfish, rude). Conversing with a highly interruptive person could also alter one's sense of what is normative in the interaction, so reciprocal interruption could be evidence of conforming to the unique norms of this interaction. Participants may have felt that it was okay or appropriate, given the confederate's behavior, to respond in kind.

In short, the results presented here do not offer compelling support for dominance complementarity. For many of the NVBs, participants reacted similarly in interruption and control conditions, and the significant effects showed participants behaving in an assertive way, rather than in a submissive way, after being interrupted. Hence, Hypothesis 1 was not supported. However, interruption, like many NVBs, is evaluated on both the vertical and the horizontal axis. Specifically, interruption is perceived as negative and undesirable (Coates 1993), hostile (LaFrance 1992), and constituting a violation of the rules in conversation (Coates). People who interrupt others, in addition to being perceived as powerful, may also be perceived as rude, confrontational, and disrespectful (Farley 2008; LaFrance 1992). It is possible that due to the strength of the manipulation, the hostile nature of interruption was more salient than the vertical implications of the behavior. Consequently, interruption (a negative hostile behavior) elicited reciprocal hostile negative reactions, which supports the horizontal predictions of the theory and Hypothesis $1 \mathrm{~b}$.

The fact that reciprocal interruption was positively correlated with disagreement and perceived confederate disrespect may shed some light into the proximal mechanisms behind the behavior. Participants did experience the interruptions as intrusive and aversive. So, it seems fair to assume that the motivations behind reciprocal interruption were competitive and/or hostile. Plausible motivations include the desire to reassert control of the floor to get one's point across or to retaliate against a disliked other.

Our two three-way interactions are somewhat complicated to interpret. For both nodding and laughter, typical gender differences emerged in the control condition, with women nodding and laughing more than men. In previous research, laughing has had a stronger association with the horizontal dimension than the vertical dimension, having been linked to attention, interest, and engagement in the conversation (Vettin and Todt 2004), as well as warmth and intimacy (McAdams et al. 1984). Our research indicated that female interrupters elicited similar levels of laughter in male and female participants, but male participants laughed much less than their female counterparts when interrupted by men. In addition, the man interrupting man condition evoked the lowest rate of laughter of all of the dyad conditions. We interpret this finding as evidence of men's discomfort with being interrupted by other men, possibly out of a concern for status implications. Because women are frequent targets of interruption, especially by men (James and Clarke 1993), and because status expectations might support greater acceptance of cross-gender interruption by women (Wagner and Berger 1997), women who were interrupted by men showed similar levels of laughter as they did in the control conditions. 
Like laughter, nodding has also been interpreted as facilitating conversation, encouraging others to speak (Hall 2006), and agreement (Helweg-Larsen et al. 2004), but there are also some associations with dominance and power - people who nod are perceived as higher in verticality than those who do not (Hall et al. 2005). Interpretation of nodding is especially complicated because situational context and different speaker motivation can produce seemingly contradictory rates of nodding (Hall). Although it is very difficult to interpret subjective states in most of our research, for the current experiment, we know how the participants perceived confederates. Regardless of interrupter gender, participants perceived interrupting confederates as influential and dominant, in addition to disrespectful and unlikable (Farley 2008). How then might we interpret the tendency for women and targets of interruption to nod more in the interruption condition than the control condition?

To examine the possibility that nodding represented different meanings for women and targets of interruption, we split the file by condition and computed intercorrelations between some of the nonverbal behaviors. In the interruption condition, nodding was only significantly associated with agreement, $r(88)=.38, p<.001$, laughter, $r(88)=.23$, $p=.03$, and latency, $r(83)=-.22, p=.04$. Those who nodded more tended to agree more, laugh more, and facilitate a speaker transition more quickly. The most parsimonious interpretation for these effects is that nodding communicated agreement, especially given that nodding and agreement were also correlated in the control condition, $r(57)=.30$, $p=.02$. It seems reasonable to assume that participants who evaluated interrupting confederates as more powerful and influential would show nonverbal agreement with their arguments. However, it is still possible that nodding reflected some degree of irritation. Knapp and Hall (2002) found that "under some circumstances nodding is a controlling behavior used to hurry another speaker along" (as cited in Hall 2006, p. 386). Our perspective is that given the experimental situation, participants nodded because (a) they did agree more in the interruption condition, and (b) they wished to facilitate a speaker transition, to show some semblance of agreement as a strategy to increase the likelihood of taking over the floor.

Given this interpretation of nodding as agreement, the three-way interaction revealed that in the control condition, women nodded (and were more agreeable) than men. However, both men and women nodded more with same-sex interrupting confederates than different-sex confederates. This finding may be related to individuals being less encouraging with interruptions from the other sex, perhaps because mixed-sex groups are likely to make status implications more salient (Carli 1990).

One limitation of the present includes the high frequency of the interruptions, the extremity of which was deemed necessary due to the theoretical considerations of status characteristics theory, the theory providing the framework for the original research (See Farley 2008). Such a high rate of interruption may not be typical in daily interaction, hurting generalizability of the findings. Because previous research has shown that there may be cultural variations with regard to how interruption is perceived (Tannen 1990), it would be beneficial for future research to include greater variability in terms of age and ethnicity. In addition, our method involved terminating the trials after all of the arguments were complete or after a certain period of silence, and if participants made fewer than three arguments, they were not included in data analysis. One of the potential reactions to repeated interruption may include a failure to continue the conversation, but because these participants were not sufficiently exposed to the manipulation, they were omitted. If certain personality variables made it more likely that one would respond to interruption with silence, then our methodology failed to capture this. 
Further research in this area should focus on the identification of proximal mechanisms of nonverbal behavior so that greater clarity on the meanings of nonverbal behavior can be gleaned. For example, it would be greatly beneficial to manipulate goals, motivations, and roles in order to determine when nodding communicates encouragement, or when it may reflect irritation (Hall 2006; Patterson 2006). For example, future studies might emphasize a competitive motive ("convince the other person you are right") versus an affiliative motive ("get along as well as possible") to determine if there are differing patterns of nonverbal reactions. Alternatively, experimenters could instruct dyads that objective observers will rank their task performance, versus their interpersonal skill with their interaction partner, versus their ability to work as a group, and examine how NVBs were differentiated across condition.

Acknowledgments The authors would like to thank Tom Mitchell and Alan Arrowsmith for their helpful comments on this manuscript.

\section{References}

Abele, A. E. (2003). The dynamics of masculine-agentic and feminine-communal traits: Findings from a prospective study. Journal of Personality and Social Psychology, 85, 768-776. doi:10.1037/00223514.85.4.768.

Aguinis, H., \& Henle, C. A. (2001). Effects of nonverbal behavior on perceptions of a female employee's power bases. Journal of Social Psychology, 141, 537-549.

Anderson, K. J., \& Leaper, C. (1998). Meta-analyses of gender effects on conversational interruption: Who, what, when, where, and how. Sex Roles, 39, 225-252. doi:10.1023/A:1018802521676.

Aries, E. J. (1982). Verbal and nonverbal behavior in single-sex and mixed-sex groups: Are traditional sex roles changing? Psychological Reports, 51, 127-134.

Aries, E. (1987). Gender and communication. In P. Shaver \& C. Hendrick (Eds.), Sex and gender (pp. 149-176). Newbury Park, CA: Sage.

Aries, E. (1996). Men and women in interaction: Reconsidering the differences. New York, NY: Oxford University Press.

Aries, E. J., Gold, C., \& Weigel, R. H. (1983). Dispositional and situational influences on dominance behavior in small groups. Journal of Personality and Social Psychology, 44, 779-786. doi:10.1037/ 0022-3514.44.4.779.

Bilous, F. R., \& Krauss, R. M. (1988). Dominance and accommodation in the conversational behaviours of same- and mixed-gender dyads. Language and Communication, 8, 183-194. doi:10.1016/02715309(88)90016-X.

Bluhm, C., Widiger, T. A., \& Miele, G. M. (1990). Interpersonal complementarity and individual differences. Journal of Personality and Social Psychology, 58, 464-471. doi:10.1037/0022-3514.58.3.464.

Burgoon, J. K., \& Dillman, L. (1995). Gender, immediacy, and nonverbal communication. In P. J. Kalbfleisch \& M. J. Cody (Eds.), Gender, power, and communication in human relationships (pp. 63-81). Hillsdale, NJ: Lawrence Erlbaum Associates.

Burgoon, J. K., \& Dunbar, N. E. (2000). An interactionist perspective on dominance-submission: Interpersonal dominance as a dynamic, situationally contingent social skill. Communication Monographs, 67, 96-121.

Burgoon, J. K., \& Le Poire, B. A. (1999). Nonverbal cues and interpersonal judgments: Participant and observer perceptions of intimacy, dominance, composure, and formality. Communication Monographs, $66,105-124$.

Carli, L. (1989). Gender differences in interaction style and influence. Journal of Personality and Social Psychology, 56, 565-576.

Carli, L. L. (1990). Gender, language, and influence. Journal of Personality and Social Psychology, 59, 941-951.

Chartrand, T., \& Bargh, J. (1999). The chameleon effect: The perception-behavior link and social interaction. Journal of Personality and Social Psychology, 76, 893-910. doi:10.1037/0022-3514.76.6.893.

Coates, J. (1993). Women, men and language (2nd ed.). New York, NY: Longman Group. 
Dunbar, N. E., Bippus, A. M., \& Young, S. L. (2008). Interpersonal dominance in relational conflict: A view from dyadic power theory. Interpersona, 2, 1-33.

Farley, S. D. (2008). Attaining status at the expense of likability: Pilfering power through conversational interruption. Journal of Nonverbal Behavior, 32, 241-260. doi:10.1007/s10919-008-0054-x.

Halberstadt, A. G., \& Saitta, M. B. (1987). Gender, nonverbal behavior, and perceived dominance: A test of the theory. Journal of Personality and Social Psychology, 53, 257-272. doi:10.1037/00223514.53.2.257.

Hall, J. A. (2006). Nonverbal behavior, status, and gender: How do we understand their relations? Psychology of Women Quarterly, 30, 384-391. doi:10.1111/j.1471-6402.2006.00313.x.

Hall, J. A., Carter, J. D., Jimenez, M. C., Frost, N. A., \& Smith LeBeau, L. (2002a). Smiling and relative status in news photographs. Journal of Social Psychology, 142, 500-510.

Hall, J. A., Coats, E. J., \& Smith LeBeau, L. (2005). Nonverbal behavior and the vertical dimension of social relations: A meta-analysis. Psychological Bulletin, 131, 898-924. doi:10.1037/0033-2909.131.6.898.

Hall, J. A., \& Friedman, G. B. (1999). Status, gender, and nonverbal behavior: A study of structured interaction between employees of a company. Personality and Social Psychology Bulletin, 25, 1082-1091. doi:10.1177/01461672992512002.

Hall, J. A., Horgan, T. G., \& Carter, J. D. (2002b). Assigned and felt status in relation to observer-coded and participant-recorded smiling. Journal of Nonverbal Behavior, 26, 63-81. doi:10.1023/ A:1015683720462.

Helweg-Larsen, M., Cunningham, S. J., Carrico, A., \& Pergram, A. M. (2004). To nod or not to nod: An observational study of nonverbal communication and status in female and male college students. Psychology of Women Quarterly, 28, 358-361. doi:10.1111/j.1471-6402.2004.00152.x.

Henley, N. M. (1977). Body politics: Power, sex and nonverbal communication. Englewood Cliffs, NJ: Prentice-Hall.

Henley, N. M. (1995). Body politics revisited: What do we know today? In P. J. Kalbfleisch \& M. J. Cody (Eds.), Gender, power, and communication in human relationships. Hillsdale, NJ: Lawrence Erlbaum Associates.

Ho, R., \& Mitchell, S. (1982). Students' nonverbal reaction to tutors' warm/cold nonverbal behavior. The Journal of Social Psychology, 118, 121-130.

James, D., \& Clarke, S. (1993). Women, men, and interruptions: A critical review. In D. Tannen (Ed.), Gender and conversational interaction (pp. 231-280). New York, NY: Oxford University Press.

Jones, T. S., \& Remland, M. S. (1993). Nonverbal communication and conflict escalation: An attributionbased model. The International Journal of Conflict Management, 4, 119-137. doi:10.1108/eb022723.

Kennedy, C. W., \& Camden, C. (1983). A new look at interruptions. Western Journal of Speech Communication, 47, 45-58.

Kiesler, D. J. (1983). The 1982 interpersonal circle: A taxonomy for complementarity in human transactions. Psychological Review, 90, 185-214. doi:10.1037/0033-295X.90.3.185.

Kollock, P., Blumstein, P., \& Schwartz, P. (1985). Sex and power in interaction: Conversational privileges and duties. American Sociological Review, 50, 34-46.

LaFrance, M. (1992). Gender and interruptions: Individual infraction or violation of the social order? Psychology of Women Quarterly, 16, 497-512. doi:10.1111/j.1471-6402.1992.tb00271.x.

McAdams, D. P., Jackson, R. J., \& Kirshnit, C. (1984). Looking, laughing, and smiling in dyads as a function of intimacy motivation and reciprocity. Journal of Personality, 52, 261-273. doi:10.1111/ j.1467-6494.1984.tb00881.x.

Moscowitz, D. S., Ho, M. H., \& Turcotte-Tremblay, A. (2007). Contextual influences on interpersonal complementarity. Personality and Social Psychology Bulletin, 33, 1051-1063. doi:10.1177/ 0146167207303024.

Mulac, A., \& Bradac, J. J. (1995). Women's style in problem solving interaction: Powerless, or simply feminine? In P. J. Kalbfleisch \& M. J. Cody (Eds.), Gender, power, and communication in human relationships (pp. 83-104). Hillsdale, NJ: Lawrence Erlbaum Associates.

Patterson, M. L. (2006). The evolution of theories of interactive behavior. In V. Manusov \& M. L. Patterson (Eds.), The Sage handbook of nonverbal communication (pp. 21-39). Thousand Oaks, CA: Sage Publications.

Ridgeway, C. L. (1987). Nonverbal behavior, dominance, and the basis of status in task groups. American Sociological Review, 52, 683-694.

Robinson, L. F., \& Reis, H. T. (1989). The effects of interruption, gender, and status on interpersonal perceptions. Journal of Nonverbal Behavior, 13, 141-153. doi:10.1007/BF00987046.

Sadler, P., \& Woody, E. (2003). Is who you are who you're talking to? Interpersonal style and complementarity in mixed-sex interactions. Journal of Personality and Social Psychology, 84, 80-96. doi:10.1037/0022-3514.84.1.80. 
Smith-Lovin, L., \& Brody, C. (1989). Interruptions in group discussions: The effects of gender and group composition. American Sociological Review, 54, 424-435. doi:10.2307/2095614.

Stapel, D. A., \& Van der Zee, K. I. (2006). The self salience model of other-to-self effects: Integrating principles of self-enhancement, complementarity, and imitation. Journal of Personality and Social Psychology, 90, 258-271. doi:10.1037/0022-3514.90.2.258.

Strong, S. R., Hills, H. I., Kilmartin, C. T., DeVries, H., Lanier, K., Nelson, B. N., et al. (1988). The dynamic relations among interpersonal behaviors: A test of complementarity and anticomplementarity. Journal of Personality and Social Psychology, 54, 798-810. doi:10.1037/0022-3514.54.5.798.

Tannen, D. (1990). You just don't understand: Women and men in conversation. New York, NY: Ballantine.

Tannen, D. (1993). The relativity of linguistic strategies: Rethinking power and solidarity in gender and dominance. In D. Tannen (Ed.), Gender and conversational interaction (pp. 165-188). New York, NY: Oxford University Press.

Tiedens, L. Z., \& Fragale, A. R. (2003). Power moves: Complementarity in dominant and submissive nonverbal behavior. Journal of Personality and Social Psychology, 84, 558-568. doi:10.1037/00223514.84.3.558.

Tiedens, L. Z., Unzueta, M. M., \& Young, M. J. (2007). An unconscious desire for hierarchy? The motivated perception of dominance complementarity in task partners. Journal of Personality and Social Psychology, 93, 402-414. doi:10.1037/0022-3514.93.3.402.

Tracey, T. J. (1994). An examination of the complementarity of interpersonal behavior. Journal of Personality and Social Psychology, 67, 864-878. doi:10.1037/0022-3514.67.5.864.

Vettin, J., \& Todt, D. (2004). Laughter in conversation: Features of occurrence and acoustic structure. Journal of Nonverbal Behavior, 28, 93-115. doi:10.1023/B:JONB.0000023654.73558.72.

Wagner, D. G., \& Berger, J. (1997). Gender and interpersonal task behaviors: Status expectation accounts. Sociological Perspectives, 40, 1-32.

Welsh, P. (1999, January 19). Colleges need higher standards, not high school warranties. USA Today, p. $17 \mathrm{~A}$ 